\begin{tabular}{lccr} 
Sivas Cumhuriyet Üniversitesi İktisadi ve İdari Bilimler Dergisi & 2020 & Cilt: 21 & Sayı: 2 \\
\hline Sivas Cumhuriyet University Journal of Economics and Administrative Sciences & 2020 & Volume: 21 & No: 2 \\
Araştırma Makalesi / Research Paper & DOI:10.37880/cumuiibf.670770
\end{tabular}

\title{
HUZUR VE DOĞRUDAN YABANCI SERMAYE İLIŞKİSİ: GELISSMEKTE OLAN ÜLKELER AÇISINDAN BİR İNCELEME
}

\author{
Kemal EYÜBOĞLU' ${ }^{1}$ \\ Enis TÜYSÜZ²
}

\begin{abstract}
ÖZET
Liberalleşmenin ticari hayatta etkisini göstermesiyle birlikte doğrudan yabancı yatırımların önemi ülkeler tarafından anlaşılmaya başlamıştır. Özellikle gelişmekte olan ülkeler, yabancı sermaye akışını kendi ülkelerine çekebilmek için buna uygun strateji ve politikalar uygulamaya koymaktadır. Çalışmada, gelişmekte olan ülkelerde (Türkiye, Rusya, Brezilya, Hindistan, Nijerya, Pakistan ve Endonezya) huzur ile doğrudan yabancı yatırım girişleri arasındaki ilişki, 2006-2017 dönemi ele alınarak analiz edilmiştir. Huzura ilişkin veriler Ekonomi ve Huzur Enstitüsü tarafından 2007'den beri yayınlanan Küresel Huzur Endeksi ile ölçülmüştür. Ayrıca çalışmada ekonomik büyüme, pazar büyüklüğü ve ticari açıklık kontrol değişkenleri de modele eklenmiştir. Değişkenler arasındaki uzun dönemli ilişki Westerlund (2007) panel eşbütünleşme testİ ile analiz edilmiştir. Eşbütünleşme testi sonuçları, değişkenlerin uzun dönemde birlikte hareket ettiklerini göstermiştir. FMOLS ve CCEMG tahmincileri ise, ülkede huzur seviyesinin artmasının, gelişmekte olan ülkelerdeki doğrudan yabancı girişleri üzerinde pozitif bir etkisi olduğunu ortaya koymuştur. Buna göre huzur seviyesinin artması ülkeye yabancı sermaye girişini hızlandıracaktır.
\end{abstract}

Anahtar Kelimeler: Küresel Huzur Endeksi, Doğrudan Yabancı Sermaye, Gelişmekte Olan Ülkeler, Panel Veri Analizi

\section{THE RELATIONSHIP BETWEEN PEACE AND FOREIGN DIRECT INVESTMENT: A STUDY ON DEVELOPING COUNTRIES}

\begin{abstract}
With the effect of liberalization in commercial life, the importance of foreign direct investments has started to be understood by countries. Especially developing countries are implementing appropriate strategies and policies in order to attract foreign capital flow to their countries. In this study the nexus between peace and foreign direct investment inflows are analyzed covering the 2006-2017 period in developing countries (Turkey, Russia, Brazil, India, Nigeria, Pakistan and Indonesia). The data on peace have been measured by the Global Peace Index published since 2007 by the Institute of Economy and Peace. In addition, economic growth, market size and trade openness control variables are also added to the model in the study. The long-term relationship between variables has been analyzed by Westerlund (2007) panel cointegration test. The cointegration test results showed that the variables move together in the long run. FMOLS and CCEMG estimators have found that increasing the peace level has a positive effect on foreign direct inflows in developing countries. Accordingly, increasing the level of peace will accelerate the foreign capital entry into the country.
\end{abstract}

Keywords: Global Peace Index, Foreign Direct Investment, Developing Countries, Panel Data Analysis

\section{GİRIŞ̧}

Doğrudan yabancı yatırım (DYY), bir ülkedeki firmaların veya bireylerin başka bir ülkede bulunan iş alanlarına yaptı̆ğ yatırımlardır. Genel olarak, bir yatırımcı yabancı ticari

${ }^{1}$ Doç. Dr., Tarsus Üniversitesi, Uygulamalı Bilimler Fakültesi, Finans ve Bankacılık Bölümü, kemaleyuboglu@tarsus.edu.tr, ORCID: 0000-0002-2108-9732

${ }^{2}$ Yüksek lisans öğrencisi, Karadeniz Teknik Üniversitesi, SBE, İşletme Bölümü, enistuysuz061@ hotmail.com ORCID: 0000-0001-9999-1067 
faaliyetler kurduğunda veya yabancı bir şirkete sahip olma ya da menfaatin kontrolü de dâhil olmak üzere ticari varlık edindiğinde DYY gerçekleşir. Dünya genelinde küreselleşme sürecinin başlamasıyla birlikte ekonomi ve ticarette liberalleşme hareketleri de hız kazanmıştır. Bu süreç ile birlikte sürdürülebilir ekonomik büyüme ve kalkınma için DYY'nin taşıdığı önem özellikle gelişmekte olan ülkeler için fark edilmiştir. DYY'nin öneminin anlaşılmasıyla beraber ülkeler bu yatırımları kendi bünyelerine çekmek için mevcut pazar ortamlarını daha cazip hale getirecek strateji ve politikalar uygulamaya başlamışlardır (Özcan ve Ar1, 2010: 66).

DYY'ler, ilk dönemlerinde gelişmiş ülkelere yoğun olarak gitmelerine karşın; 1980'li y1llardan sonra gelişmekte olan ülkelere doğru bir yönelme söz konusu olmuştur. Birleşmiş Milletler' in Dünya Yatırım Raporuna (2015) göre, gelişmekte olan ülkeler dünya çapındaki DYY'lerin \%55'ini kendilerine çekmektedir (Nur ve Dilber, 2017: 16). DYY hem sermaye sahibi ülkeye hem de yatırım yapılan ülkeye birçok avantaj sağlamaktadır. Özellikle gelişmekte olan ülkeler sürdürülebilir kalkınma için tasarruflara ihtiyaç duyarlar ve bu tasarrufları sadece kendi kaynaklarından değil yurt dışı kaynaklardan da sağlamaya çalışırlar. Ülkeler DYY'nin sağladığı avantajlara sahip olmak ve iktisadi belirsizliklere karşı ayakta kalabilecek bir ekonomik yapıya kavuşmak için DYY'leri kendi pazarlarına çekmeye yönelik çeşitli politika ve stratejiler geliştirirler. DYY, yatırım yapılan ülke için işsizlik sorununu gidermeye yönelik katkıda bulunur, ülkeye yeni teknoloji girişi gerçekleşmesini ve mevcut doğal kaynakların etkin kullanımı sağlar. Bunların yanında dış ticaret açığının azaltılmasına ve ekonomik büyümenin hızlanmasına destek olur. DYY, yatırımı yapan ülkeye ise yeni dış pazarlara açılma ve hammaddeye yakınlık gibi faydalar sağlamaktadır (Çütçü ve Kan, 2018: 2).

Yatırım yapmak isteyen sermaye sahipleri, yatırım yapacağı ülke seçiminde karar verirken göz önünde bulunduracağı bazı önemli faktörler vardır. Fakat bu faktörler ülkeden ülkeye ve dönemden döneme farklılıklar gösterebilmektedirler. Çünkü her ülkenin yatırım için aradığ 1 uygun şartlar birbirinden farklılık gösterebilmektedir. Gelişmekte olan ülkelere yapılan DYY'leri etkileyen faktörlere yönelik literatürde birçok çalışma yapılmıştır. Bu çalışmalardan elde edilen sonuçlara göre sermaye sahibi ülkelerin yatırım yapmak istedikleri ülkelerde dikkat ettikleri faktörler ekonomik istikrar, vergiler, ekonomik büyüme, hukuk, güvenlik, döviz kurları, enflasyon, ucuz hammadde ve enerji, pazara yakınlık durumu ve bürokrasinin yoğunluğu gibi faktörlerdir (Dawson, 1998; Busse, 2003; Yang, 2007; Bahar, 2010, Satorvic ve Muslija, 2017; Yorulmaz vd., 2018; Acaravcı vd., 2018). Bu faktörlerin 
yanında yatırımın yapılacağı ülkenin piyasa hacmi, işgücü maliyeti ve sahip olduğu mevcut altyapı sistemleri de önem arz etmektedir. Tüm bu faktörlerin yatırımın geleceği ile ilgili belirleyici unsurlar olduğu bilinmektedir (Nur ve Dilber, 2017: 17).

Literatürde DYY ile birçok faktörün (demokrasi, ekonomik özgürlük, turizm gibi) ilişkisi araştırılmıştır. Bu çalışmada ise diğer çalışmalardan farklı olarak yatırım yapılacak ülkedeki huzur ortamının DYY girişleri üzerindeki etkisi incelenmiştir. Yazarlarca yapılan literatür taramasına göre huzur-DYY ilişkisine yönelik bir çalışma bulunamamıştır. Çalışmada ülkelerdeki huzurun ölçüsü olarak Ekonomi ve Huzur Enstitüsü tarafindan 2007'den beri yayınlanan Küresel Huzur Endeksi (Global Peace Index) kullanılmıştır. Yüksek huzur endeksi puanı, ülkede huzur ortamının düşük olduğu anlamına gelirken, düşük huzur puanı ülkedeki huzur ortamının yüksek olduğunu ifade etmektedir. Ayrıca çalışmada yatay kesit bağımlılığını ve heterojenliği dikkate alan ikinci nesil panel eşbütünleşme testi kullanılmıştır. Böylece sonuçlarının daha güvenilir olması sağlanmıştır. Çalışmadan elde edilecek sonuçların politika yapıcılara önemli ipuçları sağlayacağı düşünülmektedir. Çünkü DYY girişleri için ev sahibi ülkede yatırım dostu ve elverişli bir ortam gereklidir (Buckley vd., 2002).

Çalışmanın geri kalanı şu şekilde düzenlenmiştir. Bir sonraki bölümde DYY ile ilişkisi araştırılan çalışmalar özetlenmiştir. 3. bölümde çalışmada kullanılan veri ve metodoloji açıklanmıştır. 4. bölümde ise çalışmadan elde edilen bulgular sunulmuştur. Son bölümde ise çalışma özetlenmiş ve politika önerilerinde bulunulmuştur.

\section{LITERATÜR TARAMASI}

Literatürde DYY ile bazı değişkenler arasındaki ilişki farklı ülkeler ve farklı zaman dilimleri açısından ele alınmıştır. Literatürde demokrasi ile DYY arasındaki ilişkiyi inceleyen çalışmaların birçoğunda iki değişken arasında pozitif yönlü bir ilişki olduğu belirlenmiştir. Örneğin, Busse (2003) DYY ile demokrasi arasındaki ilişkiyi panel veri analizi ile incelemiştir. Gelişen 69 ülkenin ele alındığı çalışmanın analiz dönemi 1972-1999 yı1ları arasını kapsamaktadır. Analiz sonucunda DYY'lerin demokratik ülkelere daha yoğun şekilde girdiği tespit edilmiştir. Li ve Resnick (2003) demokratik kurumların DYY üzerinde bir etkisinin olup olmadığını araştırmışlardır. Bu doğrultuda 1982-1985 dönemi verilerinin kullanıldığı çalışmada gelişmekte olan 53 ülke ele alınmış ve demokrasinin DYY girişlerini etkilediği sonucuna ulaşmışlardır. Guerin ve Manzocchi (2009) 1992-1994 dönemi için gelişmekte olan ülkelere yapılan DYY'lerde ev sahibi ülkelerdeki siyasi rejimin etkisinin olup 
olmadığını incelemişlerdir. Analiz sonuçları ev sahibi ülkedeki demokrasi oranının DYY miktarını pozitif yönde etkilediğini göstermiştir. Arslan ve Ökten (2010) 1970-2010 dönemi için Johansen eşbütünleşme yöntemini kullanarak DYY ile demokrasi arasındaki ilişkiyi analiz etmişlerdir. Analiz sonuçları DYY ile demokrasi arasında uzun dönemli bir ilişsi olduğunu göstermiştir. Ayrıca, demokrasiden doğrudan yabancı yatırımlara doğru tek yönlü bir nedensellik ilişkisi olduğu belirlenmiştir. Asiedu ve Lien (2011) ev sahibi ülkenin sahip olduğu doğal kaynakların demokrasi ve DYY arasındaki ilişkiyi değiştirip değiștirmediğini incelemişlerdir. Demokrasi ile DYY arasındaki ilişkinin, kaynak ihracatı yapan ve yapmayan ülkeler için aynı olduğu sonucuna ulaşmışlardır. Panel veri analizi ile 112 gelişmekte olan ülke için 1982-2007 dönemi verilerinin kullanıldığı çalışmada, 90 ülkede demokrasi artışının DYY'leri arttırdığı, 22 ülkede ise bu artışın DYY'leri azalttı̆̆ı sonucuna varılmıştır. Buna ek olarak, demokrasinin DYY üzerindeki etkisinin doğal kaynakların türüne değil büyüklüğüne bağl1 olduğu tespit edilmiştir.

Molaei ve Ahmadi (2013) demokrasi ve DYY arasındaki ilişkiyi 36 gelişmiş, 68 gelişmekte olan ve en az gelişmiş ülke grupları açısından incelemiştir. 1995-2010 döneminin ele alındığ 1 çalışmada panel veri yöntemi kullanılmıştır. Çalışma sonucunda elde edilen bulgulara göre demokrasinin DYY üzerindeki etkisi gelişmiş ülkeler için pozitif, gelişmekte olan ülkeler için negatif, en az gelişmiş ülkeler için ise istatistiksel açıdan anlamsızdır. Derbali vd. (2015) yaptıkları çalışmada demokratik geçiş ile DYY arasındaki ilişkiyi analiz etmişlerdir. 1980-2010 yılları arasında 173 ülke (44 tanesi demokratik geçiş yaşamış) verileri ele alınmıştır. Çalışma sonucunda demokratik geçişlerin DYY'leri pozitif yönde etkilediği ve doğrudan yabancı yatırımlarda önemli artışa sebep olduğu tespit edilmiştir. DYY ile demokrasi arasında herhangi bir ilişki olmadığını tespit eden çalışmalar da literatürde yer almaktadır. Resnick (2001) çalışmasında demokrasi ile DYY ilişkisini Asya, Latin Amerika ve Karayipler özelinde araştırmıştır. Çalışma sonucunda demokrasi ile doğrudan yabancı yatırımlar arasında negatif bir ilişki tespit edilmiştir. Yang (2007) 1983-2002 dönemi için siyasi rejimler ile DYY ilişkisini 134 ülkeden oluşan bir örneklem için incelemiştir. Analiz sonucunda demokrasi ve DYY arasında ilişki olduğuna dair herhangi bir bulgu elde edilememiştir. Okafor vd. (2011) Sahraaltı Afrika ülkeleri için DYY ve demokrasi arasındaki ilişkiyi test etmişlerdir. EKK ile 1996-2008 dönemi verileri kullanılmış ve örneklem 48 Afrika ülkesinden oluşturulmuştur. Çalışma sonucunda demokrasi ile DYY arasında negatif bir ilişki olduğu belirlenmiştir. 
Literatürde bazı çalışmalar ise DYY ile turizm arasındaki ilişkiyi incelemiştir. Tang vd. (2007) DYY ile turizm arasındaki ilişkiyi Çin açısından araştırmışlardır. Değişskenler arasındaki olası nedensellik ilişkisinin analizi için Granger nedensellik testi kullanılmıştır. Yapılan çalışma sonucunda DYY'den turizme tek yönlü bir nedensellik bulunmuştur. Craigwell ve Moore (2007) çalışmalarında Gelişmekte Olan Ada Devletleri'nde (SIDS), DYY ve turizm arasındaki ilişkiyi test etmişlerdir. $\mathrm{Bu}$ doğrultuda çalışmalarında panel nedensellik analizi uygulamışlardır. Analiz sonuçlarına göre, değişkenler arasında çift yönlü nedensellik olduğu belirlenmiştir. Fakat bu ilişki ülke grupları için farklılık göstermiştir. Değişkenler arasındaki nedensellik ilişkisi çoğunlukla DYY'den turizme doğrudur. Bahar (2010) çalışmasında turizmden elde edilen DYY ile ekonomik büyüme arasında uzun dönemde bir ilişki olup olmadığını Türkiye örnekleminde araştırmıştır. Çalışmada EKK yöntemi ve 19862006 yıllarına ait yıllık veriler kullanılmıştır. Çalışmanın sonucunda Türkiye’nin turizmden elde ettiği DYY ile ekonomik büyüme arasında pozitif yönlü bir ilişki olduğu belirlenmiştir.

Can ve Çoban (2013) 1963-2010 dönemi Türkiye için yaptıkları çalışmada turizm ile ekonomik büyüme arasında ilişkiyi araştırmışlardır. Çalışmada değişkenler arasında uzun dönemde bir ilişki olmadığı tespit edilmiştir. Ayrıca turizmin ekonomik büyümenin nedeni olduğu belirlenmiştir. Rajapakse (2016) çalışmasında Sri Lanka için DYY ile gayri safi yurt içi hasıla (GSYİH) ve turist sayısı arasındaki ilişkiyi araştırmıştır. Analiz için 1985-2014 dönemi verilerini kullanmış ve DYY, GSYİH ve turist sayısı arasında eşbütünleşme olmadığı tespit edilmiştir. Ayrıca, Granger nedensellik testi sonucuna göre DYY ile turist sayısı ve DYY ile GSYİH arasında çift yönlü bir nedensellik ilişkisi olduğu sonucuna varılmıştır. Işık (2016) 1985-2014 dönemi için turizm harcamaları, DYY ve ekonomik büyüme arasındaki ilişkiyi Türkiye açısından ele almıştır. Elde edilen sonuçlar turizm harcamalarından ekonomik büyümeye çift yönlü; turizm harcamalarından DYY'ye doğru tek yönlü ve DYY'den ekonomik büyümeye doğru çift yönlü bir ilişki olduğunu göstermiştir. Satrovic ve Muslija (2017) 1995-2015 dönemini ele alarak Johansen testi kullanmış ve turizm ile DYY arasındaki ilişkiyi Türkiye için incelemişlerdir. Çalışma sonucunda elde edilen bulgulara göre DYY ile turizm arasında uzun dönemli bir ilişki olduğu belirlenmiştir. Ayrıca Granger nedensellik testi sonuçlarına göre turizmden DYY'ye doğru bir nedensellik ilişkisi olduğu tespit edilmiştir. Şahbaz ve Mizrak (2017) 1974-2014 dönemi için eşbütünleşme ve nedensellik testleri kullanarak Türkiye'de DYY ile turizm gelirleri arasında kısa ve uzun dönemli bir ilişki olup olmadığı araştırılmıştır. Çalışmanın sonucunda turizm gelirleri ile DYY arasında uzun 
dönemli bir ilişki olduğu tespit edilmiştir. Bunun yanında, DYY'lerdeki artışın turizm gelirlerini pozitif yönde etkilediği sonucuna varılmıştır.

Literatürde DYY ile ilişkisi incelenmiş bir diğer değişken ise ekonomik özgürlüktür. $\mathrm{Bu}$ çalışmaların birçoğunda ekonomik özgürlük ile DYY arasında pozitif ilişki olduğu sonucuna varılmıştır. Örneğin Dawson (1998) çalışmasında 1975-1990 dönemi için tüm ülkelerde kurumlar, yatırımlar ve büyüme arasındaki ilişkiyi incelemiştir. Verilerin analizi için panel regresyon modelini kullanmıştır. Analiz sonuçlarına göre ekonomik özgürlüğün yatırımlar üzerinde dolaylı bir etkiye sahip olduğu ve bu etki yoluyla da ekonomik büyümeyi de etkilediği tespit edilmiştir. Bengoa ve Sanchez-Robles (2003) 1970-1999 dönemi verileri ile panel regresyon analizi kullanarak ekonomik özgürlük ile DYY ve ekonomik büyüme arasındaki ilişkiyi Latin Amerika'da bulunan 18 ülke açısından araştırmışlardır. Çalışmada ev sahibi ülkenin ekonomik özgürlüğü ile ev sahibi ülkeye gerçekleştirilen DYY arasında pozitif bir ilişki olduğu sonucuna varmıştır. Aynı zamanda ev sahibi ülkenin ekonomik büyümesi ile ev sahibi ülkeye yapılan DYY arasında pozitif bir ilişki olduğu belirlenmiştir.

Dawson (2003) yaptığı çalışmasında ekonomik özgürlük ve ekonomik büyüme arasında bir nedensellik ilişkisi olup olmadığını araştırmıştır. Analiz için 1970-2000 yılları arasında verisi olan tüm ülkeler örnekleme dahil edilmiş ve panel nedensellik analizi kullanılmıştır. Analiz sonucunda, değişkenler arasında karşılıklı etkileşim olduğu tespit edilmiştir. Diğer bir ifade ile genel ekonomik özgürlük seviyesinin büyümeye neden olduğu ve özgürlükteki değişimlerin büyüme ile belirlendiği ifade edilmiştir.

Kobeissi (2005) 1990-2001 dönemi için panel regresyon analizi kullanarak MENA ülkeleri için yönetişim, yasal çerçeve ve ekonomik özgürlükler gibi faktörlerin DYY üzerindeki etkilerini incelemiştir. Analiz sonucunda ekonomik özgürlüğün DYY üzerinde pozitif etkiye sahip olduğu ifade edilmiştir. Gvartney vd. (2006) 1980-2000 verileri dikkate alınarak 94 ülke için ekonomik özgürlük seviyesi ile DYY düzeyi arasındaki ilişkiyi incelemek için panel regresyon analizi uygulamışlardır. Analiz sonucunda ekonomik özgürlük seviyesi ile DYY düzeyi arasında pozitif bir ilişki olduğu tespit edilmiştir. Ayrıca ekonomik özgürlük ile ekonomik büyüme arasında da pozitif bir ilişki olduğu, ekonomik büyümenin özgürlük üzerinde pozitif bir etkisi olduğu sonucuna ulaşılmıştır. Savaşan ve Dursun (2006) 101 ülke için DYY ile ekonomik özgürlükler arasındaki etkileşimi incelemişlerdir. Çalışma sonucunda, ekonomik özgürlük seviyesi yüksek olan ülkelerin, seviyesi düşük olanlara oranla daha fazla DYY çektikleri belirlenmiştir. 
Tintin (2013) panel regresyon analizi kullandığ çalışmasında 18 ülke için doğrudan yabancı yatırımlarını belirleyen ekonomik ve kurumsal faktörleri 1996-2009 dönemi verilerini ele alarak analiz etmiştir. Çalışmadan elde edilen bulgular, GSYİH, cari açık, AB üyeliği ve ekonomik özgürlük faktörlerinin DYY üzerinde pozitif bir etkiye sahip olduğunu göstermiştir. Acaravcı vd. (2018) Türkiye'de 1995-2015 dönemi verileri için ARDL modeli kullanarak ekonomik özgürlük ile DYY ve yurt içi yatırım harcamaları arasındaki uzun dönemli ilişkiyi incelemiştir. Yapılan analizler sonucunda değişkenler arasında uzun dönemli bir ilişki olduğu sonucuna varılmıştır. Ayrıca kişi başı reel gelir ile ekonomik özgürlüklerin yurt içi harcamaları pozitif yönde etkilediği tespit edilmiştir.

\section{VERİ SETİ VE YÖNTEM}

Çalışmada 2006- 2017 dönemi için 7 gelişmekte olan ülkenin (Türkiye, Rusya, Brezilya, Hindistan, Nijerya, Pakistan ve Endonezya) y1llık verilerini kullanmaktadır. Çalışmada bu 7 ülkenin seçilmesinin nedeni ilgili dönem itibariyle bu ülkelere ait değişkenlerde herhangi bir eksik veri bulunmamasıdır. Diğer gelişmekte olan ülkelerde ise bazı yıllara ait veriler eksik veya tüm dönem için hesaplanmamıştır. Doğrudan yabancı yatırım girişlerine ilişkin veriler, Dünya Bankası veri tabanından elde edilmiştir. Barış düzeyini belirlemek için Ekonomi ve Barış Enstitüsü tarafından yayınlanan Küresel Barış Endeksi verileri kullanılmıştır. Küresel Barış Endeksi verileri 2006 yılından itibaren hesaplandığından çalışmanın analiz dönemi 2006 yılından itibaren başlatılmıştır. Küresel Barış Endeksi yazarların bildiği kadarıyla makroekonomik açıdan sadece Kollias ve Papadamou (2019) tarafından turizm ile huzur arasındaki ilişkiyi araştırmak için kullanılmıştır. Yüksek huzur puanı düşük huzur ortamı anlamına gelirken, düşük huzur puanı ülkede yüksek huzur ortamı olduğu anlamına gelmektedir.

Huzurun varlığının ya da yokluğunun tespiti için 23 gösterge belirlenmiştir ve bu göstergeler 3 ana başlık altında bölümlendirilmiştir. $\mathrm{Bu} 3$ ana başlık şu şekildedir:

- Devam eden ulusal ve uluslararası çatışmalar,

- Toplumdaki emniyet ve güvenlik oran1

- Askerileşme durumu

Her bir gösterge 1-5 arası bir skalada puanlanmıştır. Endeksteki nitel göstergeler Ekonomi İstihbarat Birimi (Economics Intelligence Unit's) tarafindan puanlandırılmıştır. Nicel verilerde yine aynı ekip tarafindan yapılan tahminlere dayanmaktadır. Endeksin hesaplanmasında kullanılan ana ve alt başlıklar aşağıda ifade edilmiştir. 
a) Devam eden ulusal ve uluslararası çatışmalar

Endeksin hesaplanabilmesi için göz önünde bulundurulan 23 göstergeden 5 tanesi bu ana başlık altında ele alınmıştır. Bunlar:

- İç ve diş çatışmaların sayısı

- Dış kaynaklı çatışmaların neden olduğu tahmini ölüm sayısı

- İç kaynaklı çatışmaların neden olduğu ölüm sayısı

• Örgütlü iç çatışma seviyesi

- Komşu ülkelerle ilişkiler

b) Toplumdaki emniyet ve güvenlik oranı

23 göstergenin 10 tanesi bir ülkenin, toplumdaki suçluluk algısından insan haklarına saygıya ve cinayet ve şiddet içerikli suç oranına kadar olan güvenlik seviyesini ölçmektedir. $\mathrm{Bu}$ göstergeler:

- Toplumdaki suçluluk algısı

• Ülkedeki mülteci ve yerinden edilmiş insan sayısının nüfusa oranı

- Siyasi istikrarsızlik

- Siyasi terör ölçeği

- Potansiyel terör eylemleri

- 100.000 kişi başına düşen cinayet sayısı

- Şiddet içerikli suç seviyesi

- Şiddet gösterileri ihtimali

• 100.000 kişi başına düşen hapsedilmiş kişi sayısı

• 100.000 kişi başına düşen güvenlik görevlisi ve polis sayısı

c) Askerileşme Göstergeleri

Göstergelerden 8 tanesi askerileşme ve silaha erişim seviyesinin ölçümüne dayalıdır. Bunlar:

- GSYH'nin yüzdesi olarak askeri harcamalar

• 100.000 kişi başına düşen silahlı kuvvet elemanı

- 100.000 kişi başına düşen ana konvansiyonel silahların ithalat hacmi

- 100.000 kişi başına düşen ana konvansiyonel silahların ihracat hacmi

- Birleşmiş Milletler koruma misyonu için bütçe desteği

- 100.000 kişi başına düşen toplam ağır silah sayısı

- Hafif silahlara erişimin kolaylı̆̆

- Askeri imkan ve kabiliyet

Endeksin Ăgırlıklandırılması 
Göstergelerin her biri görece önem düzeylerine göre 1-5 ölçek aralığında puanlandırılır. Bu puanlama Tablo 1'de gösterilmiştir. Küresel Huzur Endeksi (KHE), gösterge grubundan iki alt bileşen hesaplanmıştır:

• Yurt içi huzur ölçüsü

- Yurt dişı huzur ölçüsü

Endeks hesaplanırken iç huzur ölçüsüne \%60, dış huzur ölçüsüne \%40 ağırlık uygulanarak formüle edilmiştir. İç huzur ölçüsüne daha büyük bir ağırlık verilmesinin sebebi iç huzur seviyesinin yüksek olduğu ülkelerde dış çatışmaların seviyesinin düşük olacağı görüşünün hâkim olmasıdır.

Tablo 1. Küresel Huzur Endeksi Göstergeleri ve Önem Düzeyleri

\begin{tabular}{lc}
\hline Göstergeler & Ağırlık \\
& $(\mathbf{1 - 5})$ \\
\hline İç Huzur & $60 \%$ \\
Dış Huzur & $40 \%$ \\
Toplumdaki Suçluluk Algısı & 4 \\
100.000 kişi başına düşen güvenlik görevlisi ve polis sayısı & 3 \\
100.000 kişi başına düşen cinayet sayısı & 4 \\
100.000 kişi başına düşen hapsedilmiş kişi sayısı & 3 \\
Hafif silahlara erişimin kolaylığı & 3 \\
Örgütlü iç çatışma seviyesi & 5 \\
Şiddet gösterileri ihtimali & 3 \\
Şiddet içerikli suç seviyesi & 4 \\
Siyasi istikrarsızlık & 4 \\
Siyasi terör ölçeği & 4 \\
100.000 kişi başına düşen ana konvansiyonel silahların ithalat hacmi & 4 \\
Potansiyel terör eylemleri & 2 \\
İ̧̧ kaynaklı çatışmaların neden olduğu ölüm sayısı & 1 \\
GSYıH'nin yüzdesi olarak askeri harcamalar & 5 \\
100.000 kişi başına düşen silahlı kuvvet elemanı & 5 \\
Birleşmiş Milletler koruma misyonu için bütçe desteği & 2 \\
100.000 kişi başına düşen toplam ağır silah sayısı & 2 \\
Askeri imkan ve kabiliyet & 2 \\
Ülkedeki mülteci sayısının, nüfusun yüzdesine oranı & 3 \\
Komşu ülkelerle ilişkiler & 5 \\
\hline
\end{tabular}


İç ve dış çatışmaların sayısı

Dış kaynaklı çatışmaların neden olduğu tahmini ölüm sayısı

Kaynak: Institute for Economics and Peace, Global Peace Index Report

Sonuçların ihmal edilen değişken yanlılığa (omitted bias problem) maruz kalma olasılığını en aza indirmek için 3 kontrol değişkeni (ekonomik büyüme, pazar büyüklüğü ve ticari açıklık) modele eklenmiştir. Analizlerde değişkenlerin doğal logaritmik halleri kullanılmıştır.

İlk kontrol değişkeni ekonomik büyümedir. Ekonomik büyüme, büyüme potansiyeli, yeni teknolojilere adaptasyon ve bir ülkenin iç dinamikleri, yabancı yatırımcıları ve çokuluslu şirketleri, karlı iş firsatlarından yararlanma konusunda motive etmektedir. Bu nedenle, teorik olarak, büyüme ve DYY birbirine bağlıdır (Shahzad vd., 2016). Büyüme verisi olarak 2010 sabit fiyatlı kişi başına GSYİH kullanılmıştır.

İkinci kontrol değişkeni ülkenin pazar büyüklüğüdür. Daha büyük piyasaların daha fazla DYY çekmesi muhtemeldir, çünkü yabancı yatırımcılar yatırımlarından daha fazla gelir elde edeceklerini varsayabilir (Li ve Resnick, 2003). Buna karşın, küçük piyasalar, yatırımların büyüyebileceği elverişli bir iklim sağlayamayabilir. Bu değişken toplam nüfus ile ölçülmüştür.

Son kontrol değişkeni ise ticari açıklıktır. Bir ülkedeki DYY seviyesi ülkenin sermaye hareketliliğine açıklığının derecesine de bağlıdır (Abadie ve Gardeazabal, 2008). Önceki çalışmalar, daha fazla uluslararası ticaret yapan ülkelerin daha fazla DYY alma eğiliminde olduklarını göstermiştir (Büthe ve Milner, 2008). Bu değişkeni ölçmek için, ticari açıklık (ihracat ve ithalat toplamının GSYIHH'ya oranı) verisi kullanılmıştır. Kontrol değişkenlerine ilişkin veriler Dünya Bankası veri tabanından elde edilmiştir.

Değişkenler arasındaki uzun dönemli ilişkiyi test etmeden önce her bir değişkenin durağan oldukları seviyeler belirlenecektir. Ancak panel veri analizlerinde paneli oluşturan yatay kesitler (ülkeler) arasında bağımlılığın ve katsayıların homojen olup olmaması elde edilecek sonuçları önemli ölçüde etkileyebilecektir. Bu nedenle değişkenler arasında yatay kesit bağımlılığının var olup olmadığının ve aynı zamanda eğim katsayılarının homojenliğinin incelenmesi gerekmektedir.

Değişkenler arasında yatay kesit bağımlılığının var olup olmadığı, Berusch-Pagan (1980) LM ve Pesaran (2004) CD testleriyle analiz edilebilmektedir. Berusch-Pagan (1980) LM testi dönem sayısı ülke sayısından büyük olduğunda $(T>N)$, Pesaran (2004) CD testi ise 
hem dönem sayısı ülke sayısından büyük hem de ülke sayısı dönem sayısından büyük olduğu durumlarda $(\mathrm{T}>\mathrm{N}, \mathrm{N}>\mathrm{T})$ kullanılabilmektedir.

Her 2 testte de $\mathrm{H}_{0}$ hipotezi paneli oluşturan birimler arasında yatay kesit bağımlılığ olmadığını ifade etmektedir. Testler sonucunda elde edilecek değerlerin 0,10 seviyesinde anlamlı olması durumda $\mathrm{H}_{0}$ hipotezi reddedilecektir. Diğer bir ifade ile birimler arasında yatay kesit bağımlılı̆̆ı olduğuna karar verilecektir.

Katsayılarının homojenliği ise Pesaran ve Yamagata (2008) tarafından geliştirilen Swamy testi ile incelenmiştir. $\mathrm{Bu}$ testte $\mathrm{H}_{0}$ hipotezi eğim katsayılarının homojen olduğunu ifade etmektedir. Hesaplanan değerin 0,10 seviyesinde anlamlı olması durumda $\mathrm{H}_{0}$ hipotezi reddedilecektir. Diğer bir ifade ile eğim katsayılarının heterojen olduğuna kanaat getirilecektir.

Çalışmada değişkenler arasında yatay kesit bağımlılığı bulunması ve katsayıların heterojen olması durumunda, 1. nesil birim kök ve eşbütünleşme testleri ile yapılan analiz sonuçları sapmalı ve tutarsız olabilecektir. Bu yüzden değişkenlerin durağan oldukları seviyeler Pesaran (2007) tarafından geliştirilen ve 2. nesil bir birim kök testi olan CrossSectionally Augmented Dickey Fuller (CADF) panel birim kök testi ile incelenmiştir.

Yatay kesit bağımlılığını ve heterojenliği dikkate alan CADF testi, $T>N$ ve $N>T$ durumlarında kullanılabilmektedir. CADF testinde hesaplanan değerin CADF kritik tablo değerinden büyük olması durumunda $\mathrm{H}_{0}$ hipotezi reddedilir ve değişkenin durağan olduğu sonucuna ulaş1lır.

Westerlund (2007) panel eşbütünleşme testi, yatay kesit bağımlılığını ve heterojenliği göz önünde bulunduran bir testtir. Westerlund (2007) testi hata düzeltme modeline dayalıdır ve bu test için 4 istatistik önerilmiştir. Eğim katsayılarının heterojen olması durumunda $\mathrm{G}_{\mathrm{t}} \mathrm{ve}$ $\mathrm{G}_{\mathrm{a}}$; eğim katsayılarının homojen olması durumunda ise $\mathrm{P}_{\mathrm{t}}$ ve $\mathrm{P}_{\mathrm{a}}$ sonuçları dikkate alınmalıdır.

Çalışmada uzun dönem katsayıları Pedroni (2001) tarafından geliştirilen Tam Uyarlanmış Panel EKK (Panel FMOLS) ve Pesaran (2006) tarafından geliştirilen Ortak İlişkili Etkiler Ortalama Grup (CCEMG) tahmincileri ile hesaplanmıştır. Panel FMOLS panel modelinde heterojenliğgi göz önünde bulundurabilirken yatay kesit bağımlılığını ihmal etmektedir. CCEMG tahmincisi ise yatay kesit bağımlılı̆̆ını ve heterojenliği dikkate almaktadır. Ayrıca, CCEMG tahmincisi yapısal kırılmalar olması durumunda da güvenilir sonuçlar vermektedir (Atasoy, 2017: 736). 


\section{AMPÍRIK BULGULAR}

Panel geneline ve ülkelere ilişkin tanımlayıcı istatistikler Tablo 2'de gösterilmiştir. Buna göre çalışma dönemi çerçevesinde en düşük ortalama DYY girişinin Pakistan'a, en yüksek ortalama DYY girişinin ise Brezilya’ya olduğu görülmektedir.

Huzur ortamı açısından ise ortalama en düşük huzur ortamının Pakistan'da, en yüksek huzur ortamının ise Endonezya'da olduğu belirlenmiştir. En yüksek ortalama ekonomik büyümenin Türkiye'ye, en düşük büyümenin Pakistan'a ait olduğu belirlenmiștir. Ortalama en yüksek pazar büyüklüğü Hindistan'a, en düşük pazar büyüklüğü ise Türkiye'ye aittir. Ortalama ticari açıklığın en yüksek ve en düşük olduğu ülkeler sırasıyla Türkiye ve Brezilya'dır.

Tablo 2. Panel Geneline ve Ülkelere İlişkin Tanımlayıcı İstatistikler

\begin{tabular}{|c|c|c|c|c|c|c|c|}
\hline & Değişkenler & Ortalama & Maksimum & Minimum & $\begin{array}{l}\text { Std. } \\
\text { Hata }\end{array}$ & Çarpıklık & Basıklık \\
\hline \multirow{5}{*}{ Panel } & HUZ & 0.91 & 1.15 & 0.57 & 0.17 & -0.39 & 1.97 \\
\hline & DYY & 23.43 & 25.34 & 20.57 & 1.18 & -0.38 & 2.28 \\
\hline & EKO & 8.30 & 9.61 & 6.92 & 0.96 & -0.04 & 1.37 \\
\hline & PAZ & 19.17 & 21.02 & 18.05 & 0.81 & 1.19 & 3.81 \\
\hline & Tic & 3.67 & 4.07 & 3.03 & 0.29 & -0.67 & 2.09 \\
\hline \multirow{5}{*}{ Türkiye } & HUZ & 0.91 & 1.06 & 0.82 & 0.08 & 1.16 & 0.13 \\
\hline & DYY & 23.38 & 23.82 & 22.87 & 0.31 & -0.26 & -0.87 \\
\hline & EKO & 9.39 & 9.61 & 9.21 & 0.14 & 0.20 & -1.55 \\
\hline & PAZ & 18.12 & 18.21 & 18.05 & 0.05 & 0.20 & -1.27 \\
\hline & Tic & 3.90 & 3.99 & 3.83 & 0.05 & 0.12 & -1.27 \\
\hline \multirow{5}{*}{ Rusya } & HUZ & 1.07 & 1.15 & 0.82 & 0.09 & -2.59 & 7.49 \\
\hline & DYY & 24.34 & 25.04 & 22.65 & 0.64 & -1.74 & 4.02 \\
\hline & EKO & 9.31 & 9.38 & 9.18 & 0.06 & -0.97 & 0.31 \\
\hline & PAZ & 18.78 & 18.79 & 18.78 & 0.00 & 1.33 & -0.33 \\
\hline & TiC & 3.89 & 4.00 & 3.83 & 0.06 & 0.81 & -0.59 \\
\hline \multirow{5}{*}{ Brezilya } & HUZ & 0.74 & 0.79 & 0.70 & 0.03 & 0.03 & -1.79 \\
\hline & DYY & 24.84 & 25.34 & 23.69 & 0.50 & -1.35 & 1.31 \\
\hline & EKO & 9.31 & 9.39 & 9.19 & 0.06 & -0.53 & -0.57 \\
\hline & PAZ & 19.11 & 19.16 & 19.06 & 0.03 & -0.16 & -1.10 \\
\hline & Tic & 3.21 & 3.31 & 3.10 & 0.06 & -0.29 & -0.18 \\
\hline \multirow{5}{*}{ Hindistan } & HUZ & 0.92 & 0.94 & 0.86 & 0.03 & -1.82 & 2.54 \\
\hline & DYY & 24.21 & 24.52 & 23.72 & 0.27 & -0.44 & -1.04 \\
\hline & EKO & 7.29 & 7.59 & 7.01 & 0.19 & 0.20 & -1.07 \\
\hline & PAZ & 20.95 & 21.02 & 20.87 & 0.05 & -0.15 & -1.02 \\
\hline & Tic & 3.87 & 4.02 & 3.69 & 0.12 & -0.09 & -1.35 \\
\hline
\end{tabular}




\begin{tabular}{cccccccc} 
& HUZ & 1.01 & 1.07 & 0.82 & 0.07 & -2.11 & 5.37 \\
\multirow{5}{*}{ Nijerya } & DYY & 22.45 & 22.90 & 21.87 & 0.34 & -0.24 & -0.86 \\
& EKO & 7.74 & 7.85 & 7.56 & 0.10 & -0.74 & -0.64 \\
& PAZ & 18.92 & 19.07 & 18.78 & 0.10 & 0.00 & -1.22 \\
& TiC & 3.54 & 3.98 & 3.03 & 0.30 & -0.55 & -0.65 \\
& & & & & & & \\
& HUZ & 1.09 & 1.15 & 0.99 & 0.06 & -0.79 & -0.76 \\
& DYY & 21.55 & 22.44 & 20.57 & 0.58 & 0.19 & -0.61 \\
& PKO & 6.99 & 7.11 & 6.92 & 0.06 & 1.04 & 0.14 \\
& PAZ & 18.99 & 19.10 & 18.87 & 0.08 & -0.04 & -1.29 \\
& TiC & 3.44 & 3.57 & 3.23 & 0.11 & -1.00 & -0.18 \\
& & & & & & & \\
Endondan & HUZ & 0.64 & 0.75 & 0.57 & 0.05 & 0.85 & 1.21 \\
& DYY & 23.23 & 23.95 & 22.24 & 0.68 & -0.51 & -1.70 \\
& EKO & 8.11 & 8.33 & 7.87 & 0.15 & -0.08 & -1.24 \\
& PAZ & 19.33 & 19.39 & 19.25 & 0.05 & -0.15 & -1.24 \\
& TiC & 3.86 & 4.07 & 3.62 & 0.14 & -0.29 & -0.49 \\
\hline
\end{tabular}

Tablo 3'te panel modelinin yatay kesitsel bağımlılığına ve homojenliğine ilişkin bulgular raporlanmıştır. Bulgular, yatay kesit bağımlılığını test istatistiklerinin olasılık değerlerinin 0,10 'dan küçük olduğunu göstermektedir. $\mathrm{Bu}$ durumda panelin yatay kesit bağımlılığı içermediğini ifade eden H0 hipotezi reddedilmiştir. Swamy testi sonuçları ise 0.01 seviyesinde istatistiksel açıdan anlamlı bulunmuştur. Dolayısıyla model için $\mathrm{H}_{0}$ hipotezi reddedilmiş ve eğim katsayılarının heterojen olduğuna karar verilmiştir.

Tablo 3. Yatay-kesit Bağımlılık ve Homojenlik Testi Sonuçları

\begin{tabular}{lcc}
\hline Yatay-kesit Bağımlılık Testleri & ist-değeri & p-değeri \\
\hline Breusch-Pagan LM & 54.48440 & 0.000 \\
Pesaran CD & 3.65432 & 0.001 \\
\hline Homojenlik Testi & ist-değeri & p-değeri \\
\hline$\square$ & 4.1209 & 0.000 \\
$\Delta$ & 4.4328 & 0.000 \\
\hline
\end{tabular}

Panel modeli yatay kesitsel bağımlılık ve heterojenliğe sahip olduğunun değişkenlerin durağan oldukları seviyelerin belirlenmesinde CADF panel birim kök testi kullanılmıştır. CADF bulguları Tablo 4'te rapor edilmiştir. Buna göre test değişkenlerin seviye hallerine uygulandığında $\mathrm{H}_{0}$ hipotezi reddedilememiştir. Ancak test, değişkenlerin ilk farklarına uygulandığında, $\mathrm{H}_{0}$ hipotezi tüm değişkenler için reddedilmiştir. Başka bir ifade ile değişkenlerin birinci farkında durağan oldukları tespit edilmiştir.

Tablo 4. CADF Panel Birim Kök Testi 


\begin{tabular}{|c|c|c|c|}
\hline & t-bar & $\mathrm{Z}$ [t-bar] & Olasılık Değeri \\
\hline Huzur & -1.128 & 1.413 & 0.921 \\
\hline$\Delta$ Huzur & -2.295 & -1.420 & 0.078 \\
\hline DYY & -2.121 & -0.997 & 0.159 \\
\hline$\Delta \mathrm{DYY}$ & -2.555 & -2.0520 & 0.020 \\
\hline Büyüme & -0.992 & 1.744 & 0.959 \\
\hline$\Delta$ Büyüme & -2.408 & -1.695 & 0.045 \\
\hline Pazar büyüklüğü & -1.710 & 1.286 & 0.901 \\
\hline$\Delta$ Pazar büyüklüğü & -3.429 & -2.811 & 0.002 \\
\hline Ticari Açıklık & -1.803 & -0.226 & 0.410 \\
\hline$\Delta$ Ticari Açıklık & -2.615 & -2.196 & 0.014 \\
\hline
\end{tabular}

Not: \% 1, \% 5 ve \% 10 anlamlılık seviyelerinde Pesaran (2007)'nin kritik değerleri sırasıyla $\quad-2.66,-2.37$ ve 2.22'dir.

Çalışmada değişkenler arasındaki uzun dönemli ilişkinin varlığı yatay kesit bağımlılığını ve heterojenliği dikkate alan Westerlund (2007) panel eşbütünleşme testi ile de analiz edilmiş ve test sonuçları Tablo 5 'te gösterilmiştir. Buna göre her bir test istatistiği istatistiksel açıdan 0.10 seviyesinde anlamlıdır. Diğer bir ifade ile Westerlund (2007) panel eşbütünleşme sonuçları değişkenlerin eşbütünleşik olduğuna dair kanıtlar sunmaktadır.

Tablo 5. Westerlund (2007) ECM Eşbütünleşme Testi Sonuçları

\begin{tabular}{cccc}
\hline İstatistikler & İstatistik Değeri & Z-dĕgeri & Bootstrap p-dĕ̆eri \\
\hline $\mathrm{G}_{\mathrm{t}}$ & -3.432 & -2.135 & 0.062 \\
$\mathrm{G}_{\mathrm{a}}$ & -3.938 & 1.641 & 0.043 \\
$\mathrm{P}_{\mathrm{t}}$ & -5.958 & -1.887 & 0.050 \\
$\mathrm{P}_{\mathrm{a}}$ & -4.448 & -0.075 & 0.030 \\
\hline
\end{tabular}

Not: Westerlund (2007) $\mathrm{H}_{0}$ hipotezi eşbütünleşme ilişkisinin olmadığını varsaymaktadır. Test sabitli model için tahmin edilmiştir. Bootstrap değerleri 400 replikasyon ile elde edilen olasılıkları göstermektedir.

Değişkenler arasındaki eşbütünleşme ilişkisi belirlendikten sonra Pedroni (2001) FMOLS ve Pesaran (2006) CCEMG tahmincileri ile uzun dönem katsayıları tahmin edilmiştir. FMOLS ve CCEMG tahmincilerine ilişkin katsayılar Tablo 6'da gösterilmiştir. Buna göre hem FMOLS ve hem de CCEMG tahmincilerine göre huzur endeksindeki düşüş gelişmekte olan ülkelere DYY girişlerini arttırmaktadır. Yani, huzur ortamının arttığı ülkelere DYY girişi hızlanmaktadır. Dolayısıyla, huzurun bu ülkelerde doğrudan yabancı yatırım girişi için çok önemli bir faktör olduğu görülmüştür.

Tablo 6. Uzun Dönem Katsayıları

\begin{tabular}{ccccc}
\hline \multirow{2}{*}{ Model: $\mathrm{DYY}_{\mathrm{it}}=f\left(\mathrm{HUZ}_{\mathrm{it}}, \mathrm{EKO}_{\mathrm{it}}, \mathrm{PAZ}_{\mathrm{it}}, \mathrm{TIC}_{\mathrm{it}}\right)$} & \multicolumn{2}{c}{ FMOLS } & \multicolumn{2}{c}{ CCEMG } \\
& Katsay1 & Olas1lk & Katsay1 & Olas1lı \\
\hline Huzur Ortam1 & -0.568 & 0.000 & -0.683 & 0.097 \\
\hline
\end{tabular}




\begin{tabular}{ccccc}
\hline Ekonomik Büyüme & 0.761 & 0.000 & 0.793 & 0.090 \\
\hline Pazar Büyüklügü & 0.484 & 0.000 & 0.677 & 0.416 \\
\hline Ticari Açıklık & 0.135 & 0.000 & 0.051 & 0.515 \\
\hline
\end{tabular}

Aynı şekilde her iki tahminciye göre ekonomik büyümedeki artış DYY girişini arttırmaktadır. Sonuçlar, büyümekte olan ekonomilerin daha fazla getiri elde etmek için daha iyi firsatlar sağladığı için yatırımcılar tarafından tercih edildiği görüşünü desteklemektedir. Bu sonuçlar Demirhan ve Masca (2008), Ranjan ve Agrawal (2011), Guesmi ve Teulon (2013) ve Shah and Faiz (2015) 'in çalışmalarında elde ettikleri sonuçlar ile uyumludur. FMOLS tahmincisine göre pazar büyüklüğündeki ve ticari açıklıktaki artış DYY girişlerine olumlu yönde katkı sağlamaktadır. Bu sonuçlar bu sonuç Mughal ve Akram (2011), Rehman vd. (2011), Anitha (2012) ve Anwar ve Afza (2014) ile örtüşmektedir. Gelişmekte olan ülkelerinin daha büyük pazarları mal ve hizmetlere talep yaratılmasında ve ölçek ekonomilerinden yararlanılmasında yardımcı olmaktadır. Daha büyük pazar büyüklüğü daha fazla potansiyel tüketiciye yol açacak ve daha fazla fırsat sağlayacaktır. Ticari açıklık bulguları da beklenen sonuçlarla tutarlıdır. Ticari açıklık katsayısı, dışa açıklıktaki artışın DYY girişlerinin artmasına neden olduğunu göstermektedir. Bu sonuçlar Ranjan ve Agrawal (2011), Shah (2011), Srinivasan (2012), Anwar ve Afza (2014) ve Guesmi ve Teulon (2013) ve Shah ve Faiz (2015) bulgularıyla uyumludur. Sonuçlar, ticari açıklığın gelişmekte olan ülkelere DYY girişlerini çekmede önemli bir faktör olduğunu ortaya koymaktadır. Yatırımcılar daha açık ve yabancı yatırımları kabul etmeye istekli ekonomilere yatırım yapmayı tercih etmektedirler. Ancak CCEMG tahmincisine göre her iki değişkenin DYY üzerindeki etkisi istatistiksel açıdan anlamsız bulunmuştur.

\section{SONUÇ}

Liberalleşmenin ticari hayattaki etkisini göstermesiyle birlikte DYY'nin önemi ülkeler tarafından anlaşılmaya başlanmıştır. Özellikle gelişmekte olan ülkeler yabancı sermaye akışını kendi ekonomilerine çekmek için buna uygun strateji ve politikalar uygulamaya koymaktadır.

DYY gelişmekte olan ülkelerde verimlilik, istihdam ve ticaret artışı, yeni teknolojilere ulaşma (Shah, 2009; Mughal ve Akram, 2011; Azam ve Ather, 2015) gibi pek çok olumlu etki yaratmaktadır. Mevcut küreselleşme eğilimleri, gelişmekte olan ülkeleri, ekonomilerini büyütmek için nasıl daha fazla doğrudan yabancı yatırım çekeceklerine odaklanmalarını 
teşvik etmektedir. Bu durum, ancak yatırımcılar belirli bir ekonomiye yatırım yapmaya hazır olduklarında mümkündür. Yabancı yatırımcılar yatırımlarının güvende olduğunu düşündükleri ülkelere yatırım yapmayı tercih ederler.

Bir ülkedeki huzur ve güvenlik ortamı, yabancı yatırımcının yatırımı gerçekleştireceği ülke için önemli bir husustur. Çünkü yatırımcı her şeyden önce hem kendini ve hem de yatırımını güvende hissetmek istemektedir. Huzur ve emniyetin olmadığı bir ortamda yatırım yapılması rasyonel değildir.

$\mathrm{Bu}$ çalışmada huzur ile doğrudan yabancı sermaye girişleri arasındaki olası ilişkiler, 2006-2017 dönemi için bazı gelişmekte olan ülkeler (Türkiye, Rusya, Brezilya, Hindistan, Nijerya, Pakistan ve Endonezya) açısından analiz edilmiştir. Çalışmada ekonomik büyüme, pazar büyüklüğü ve ticari açıklık değişkenleri kontrol değişkenleri olarak kullanılmıştır. Öncelikle değişkenlerin durağan oldukları seviyeler CADF panel birim kök testi ile belirlenmiştir. Birinci farklarında durağan oldukları belirlenen değişkenlere Westerlund (2007) panel eşbütünleşme testi uygulanarak olası eşbütünleşme ilişkileri analiz edilmiştir. Yapılan analizler sonucunda DYY girişleri ile huzur ortamı, ekonomik büyüme, pazar büyüklüğü ve ticari açıklık arasında eşbütünleşme ilişkisi olduğu tespit edilmiştir. Ardından FMOLS ve CCEMG tahmincileri ile uzun dönem katsayıları tahmin edilmiştir. Buna göre elde edilen sonuçlar gelişmekte olan ülkelerde huzur ortamının iyileşmesinin ülkeye giren DYY'leri arttırdığını göstermiştir.

Yatırımcının gözünde bir ülkenin huzur ve güvenlik durumunu tespit etmeye yönelik bazı göstergeler bulunmaktadır. Bir ülkenin, komşu ülkeler ile olan ilişkileri bu göstergelerin önemlilerinden birisidir. Komşu ülkelerle iyi ilişkilerde bulunan ülkeler, yatırımcının gözünde pozitif izlenim bırakmaktadırlar. Ülkedeki iç ve dış kaynaklı çatışmaların ve bu çatışmaların sebep olduğu ölüm sayısı da yine önemli bir göstergedir. Ülkedeki huzur ortamının sağlanabilmesi için çatışma ve bu çatışmalardan kaynaklanan ölüm sayısının düşük olması gerekmektedir. Çatışma ortamının çok uluslu işletmelerinin yatırım kararlarını etkileme olasılığı yüksektir, çünkü bu gibi ortamlar yatırım firsatları ve karlılık üzerinde doğrudan zarar verici bir etki yaratmaktadır.

Yatırımın yapılacağı ülke toplumunun asayiş durumu ve suçluluk oranı göstergeleri de yatırımcının gözünde güvenli yatırım ortamı için önem arz etmektedir. Ülkedeki suç oranının yüksek olması, böyle bir ortama yatırım yapma konusunda tereddütler yaşatabilecektir. Bir ülkede huzur ortamının sağlanamaması çalışanların güvensiz bir ortamda daha yüksek maaş 
talep etmelerini sağlayabilir. Ayrıca ek güvenlik önlemlerine ihtiyaç duyan yabancı yatırımcılar için çekici bir yatırım ortamı oluşturmak oldukça zorlu bir hale gelecektir. Dolayısıyla gelişmekte olan ülkeler yatırımcıların arzu ettiği huzurlu ve güvenli yatırım ortamını sağladıkları takdirde, diğer faktörler sabit iken, ülkelerine yabancı sermaye çekebileceklerdir. Hükümetler bu doğrultuda, yoksulluk, okur-yazarlık, gelir eşitsizliği, vb. gibi olumsuz faktörleri ortadan kaldırmaya yönelik tedbirleri devreye sokmalıdır. Dış yatırımı çekmek için hükümetler, ülkelerin uluslararası alandaki imajını olumlu yönde etkileyecek tanıtımlar yapmalı ve kamu yatırımlarını arttırmalıdır.

İlerleyen çalışmalarda farklı dönem, ülke/ülke grupları için farklı değişkenler kullanılarak literatüre katkı sağlanabilir. 


\section{KAYNAKÇA}

Abadie, A., \& Gardeazabal, J. (2008). Terrorism and the world economy. European Economic Review, 52(1), 127.

Acaravc1, A., Artan, S., Erdoğan, S., \& Göktürk, T. B. (2018). Türkiye'de kurumsal kalite, reel gelir ve doğrudan yabancı yatırımlar ilişkisi. Mehmet Akif Ersoy Üniversitesi İktisadi ve İdari Bilimler Fakültesi Dergisi, $5(2), 132-145$.

Anitha, R. (2012). Foreign direct investment and economic growth in India. International Journal of Marketing, Financial Services \& Management Research, 1(8), 108-125.

Anwar, Z., \& Afza, T. (2014). Impact of terrorism, gas shortage and political instability on FDI inflows in Pakistan. Science International, 26(1), 507-511.

Arslan, Ü., \& Ökten, N. Z. (2010). The relations between FDI and democracy: Evidence from Turkey. International Research Journal of Finance and Economics, 56, 111-123.

Asiedu, E., \& Lien, D. (2011). Democracy, foreign direct investment and natural resources. Journal of international economics, 84(1), 99-111.

Atasoy, B. S. (2017). Testing the environmental Kuznets curve hypothesis across the US: Evidence from panel mean group estimators. Renewable and Sustainable Energy Reviews, 77, 731-747.

Azam, M., \& Ahmed, A. M. (2015). Role of human capital and foreign direct investment in promoting economic growth. International Journal of Social Economics. 42, 98-111.

Bahar, O. (2010). Turizm Sektörüne Sağlanan Doğrudan Yabancı Sermaye Yatırımlarının (DYSY) Ekonomik Büyüme Üzerine Olan Olası Etkisi: Türkiye Örneği (1986-2006). Anatolia: Turizm Arastirmalari Dergisi, 21(1), 27-40.

Bengoa, M., \& Sanchez-Robles, B. (2003). Foreign direct investment, economic freedom and growth: new evidence from Latin America. European journal of political economy, 19(3), 529-545.

Breusch, T. S., \& Pagan, A. R. (1980). The Lagrange multiplier test and its applications to model specification in econometrics. The review of economic studies, 47(1), 239-253.

Buckley, P. J., Clegg, J., Wang, C., \& Cross, A. R. (2002). FDI, regional differences and economic growth: panel data evidence from China. Transnational corporations, 11(1), 1-28.

Busse, M. (2003). Democracy and FDI. Hamburgisches Welt-Wirtschafts-Archiv (HWWA) Hamburg Institute of International Economics, Discussion Paper, 220, 1-27.

Büthe, T., \& Milner, H. V. (2008). The politics of foreign direct investment into developing countries: increasing FDI through international trade agreements? American journal of political science, 52(4), 741-762.

Craigwell, R., \& Moore, W. (2008). Foreign direct investment and tourism in SIDS: Evidence from panel causality tests. Tourism analysis, 13(4), 427-432.

Çoban, O., \& Özcan, C. C. (2013). Türkiye'de turizm gelirleri-ekonomik büyüme ilişkisi: nedensellik analizi (1963-2010). Eskişehir Osmangazi Üniversitesi İktisadi ve İdari Bilimler Dergisi, 8(1), 243-261.

Çütçü, İ., \& Kan, E. (2018). Doğrudan yabancı sermaye yatırımlarını etkileyen faktörler: Türkiye Örneği. Sakarya İktisat Dergisi, 7(3), 1-21.

Dawson, J. W. (1998). Institutions, investment, and growth: New cross-country and panel data evidence. Economic inquiry, 36(4), 603-619.

Dawson, J. W. (2003). Causality in the freedom-growth relationship. European Journal of Political Economy, 19(3), 479-495.

Demirhan, E., \& Masca, M. (2008). Determinants of foreign direct investment flows to developing countries: a cross-sectional analysis. Prague economic papers, 4(4), 356-369.

Derbali, A., Trabelsi Masmoudi, L., \& Zitouna, H. (2015). Democratic transition and foreign direct investment: Transition process matters. MPRA paper.

Guerin, S. S., \& Manzocchi, S. (2009). Political regime and FDI from advanced to emerging countries. Review of World economics, 145(1), 75-91. 
Teulon, F., \& Guesmi, K. (2013). Determinants of foreign direct investments in the South Asian Association for regional Cooperation. Journal of Applied Business Research (JABR), 29(6), 1791-1798.

Gwartney, J. D., Holcombe, R. G., \& Lawson, R. A. (2006). Institutions and the Impact of Investment on Growth. Kyklos, 59(2), 255-273.

Işık, C. (2016). Türkiye'de Turizm Harcamaları, Doğrudan Yabancı Sermaye Yatırımları ve Ekonomik Büyüme İlişkisinin Sınır Testi Yaklaşımıyla Analizi. Uluslararası Türk Dünyası Turizm Araştırmaları Dergisi, $1(1), 1-8$.

Kobeissi, N. (2005). Impact of governance, legal system and economic freedom on foreign investment in the MENA region. Journal of Comparative International Management. 8, 20-41.

Kollias, C., \& Papadamou, S. (2019). Peace and Tourism: A Nexus? Evidence from developed and developing countries. The Singapore Economic Review, 64(02), 323-339.

Li, Q., \& Resnick, A. (2003). Reversal of fortunes: Democratic institutions and foreign direct investment inflows to developing countries. International organization, 57(1), 175-212.

Molaie, B., \& Ahmadi, A. (2013). The Effect Of Democracy, Economic Stability and Political Stability on Foreign Direct Investment, Economic and Social Development: Book of Proceedings, 37-44.

Mughal, M. M., \& Akram, M. (2011). Does market size affect FDI? The Case of Pakistan. Interdisciplinary Journal of Contemporary Research in Business, 2(9), 237-247.

Nur, H. B., \& Dilber, İ. (2017). Gelişmekte Olan Ülkelerde Doğrudan Yabancı Yatırımları Belirleyen Temel Unsurlar. Dokuz Eylül Üniversitesi İktisadi İdari Bilimler Fakültesi Dergisi, 32(2), 15-45.

Okafor, C. E., Ujah, N. U., Elkassabgi, A. Y., \& Ajalie, W. U. (2011). Democracy and FDI inflow: Evidence of discordance in Sub-Saharan Africa. International Research Journal of Finance and Economics, 63, 140149.

Özcan, B., \& Ari, A. (2010). Doğrudan Yabancı Yatırımların Belirleyicileri Üzerine Bir Analiz: OECD Örneği, Ekonometri ve İstatistik e-Dergisi, 12, 65-88.

Pedroni, P. (2001). Fully modified OLS for heterogeneous cointegrated panels. In Nonstationary panels, panel cointegration, and dynamic panels. Emerald Group Publishing Limited. PESARAN, Hashem (2004), "General Diagnostic Tests for Cross Section Dependence in Panels", Cambridge Working Papers in Economics, 435-454.

Pesaran, M. H. (2006). Estimation and inference in large heterogeneous panels with a multifactor error structure. Econometrica, 74(4), 967-1012.

Pesaran, M. H. (2007). A simple panel unit root test in the presence of cross-section dependence. Journal of applied econometrics, 22(2), 265-312.

Pesaran, M. H., \& Yamagata, T. (2008). Testing slope homogeneity in large panels. Journal of econometrics, 142(1), 50-93.

RAJAPAKSE, R. (2016), (2016). The relationship between foreign direct investment and tourism development: An analysis of Granger causality. Imperial Journal of Interdisciplinary Research, 2, 987-993.

Ranjan, V., \& Agrawal, G. (2011). FDI inflow determinants in BRIC countries: A panel data analysis. International Business Research, 4(4), 255-263.

Rehman, C. A., Ilyas, M., Alam, H. M., \& Akram, M. (2011). The impact of infrastructure on foreign direct investment: The case of Pakistan. International Journal of Business and Management, 6(5), 268.

Resnick, A. L. (2001). Investors, turbulence, and transition: Democratic transition and foreign direct investment in nineteen developing countries. International Interactions, 27(4), 381-398.

Satrovic, E., \& Muslija, A. (2017, October). Foreign direct investments and tourism: Empirical evidence from Turkey, International Congress on Politic, Economic and Social Studies, 3, 88-100.

Savaşan, F., \& Dursun, İ. (2006). Ekonomik özgürlükler ve doğrudan yabancı yatırımlar: istatistiksel bir analiz, Selçuk Üniversitesi İIBF Sosyal ve Ekonomik Araştırmalar Dergisi, 6, $29-52$.

Shah, M. H. (2009). FDI induced growth in developing countries: does human capital matter. in PhD Conference, Economics Department, University of Leicester, Leicester, UK. 
Shah, M. H. (2015). Terrorism and foreign direct investment: An empirical analysis of SAARC countries. City University Research Journal, 5(2), 219-233.

Shah, M. H. (2010). Bilateral Linkages with OECD and FDI Inflows in Leading Developing Countries. International Journal of Interdisciplinary Social Sciences, 5(7), 255-270.

Shahzad, S. J. H., Zakaria, M., Rehman, M. U., Ahmed, T., \& Fida, B. A. (2016). Relationship between FDI, terrorism and economic growth in Pakistan: pre and post 9/11 analysis. Social Indicators Research, 127(1), 179-194.

Srinivasan, P. (2011). Determinants of Foreign Direct Investment in SAARC Nations: An Econometric Investigation. IUP Journal of Managerial Economics, 9(3), 26-42.

Şahbaz, A., \& Mızırak, Z. (2017). Turizm gelirleri ve doğrudan yabancı yatırımlar arasındaki ilişki: Türkiye örneği. KMÜ Sosyal ve Ekonomik Araştırmalar Dergisi, 19, 107-114.

Tang, S., Selvanathan, E. A., \& Selvanathan, S. (2007). The relationship between foreign direct investment and tourism: empirical evidence from China. Tourism economics, 13(1), 25-39.

Tintin, C. (2013). The determinants of foreign direct investment inflows in the Central and Eastern European Countries: The importance of institutions. Communist and Post-Communist Studies, 46(2), 287-298.

Westerlund, J. (2007). Testing for error correction in panel data. Oxford Bulletin of Economics and statistics, 69(6), 709-748.

Yang, B. (2007). Autocracy, democracy, and FDI inflows to the developing countries. International Economic Journal, 21(3), 419-439.

Yorulmaz, Ö., Yakut, S. G., \& Gacar, B. K. (2018). Doğrudan Yabancı Yatırımları Etkileyen Faktörlerin Çok Değişkenli İstatistiksel Yöntemler ile İncelenmesi. Uluslararası İnsan Çalışmaları Dergisi, 1(2), 63-73. 